\title{
NUEVAS ESPERANZAS DE COMUNICACIÓN PARA LA PERSONA CON AUTISMO
}

Lic. Beatriz E. González Hernández

EL PUNTO DE PARTIDA Y FIN DE TODO ACTO EDUCATIVO SIEMPRE ES LA persona humana. Por ello resulta indispensable que al inicio de cualquier investigación pedagógica este concepto sea el pilar y luz que guíe el curso de la misma.

Así, nuestra investigación va enfocada al estudio de la persona con síndrome autista y de cómo ayudar a subsanar en la medida de lo posible las limitaciones que presenta. Una de las principales limitaciones que esta persona con autismo padece es su gran incapacidad para expresar sus sentimientos, pensamientos, ideas y emociones de forma oral o escrita y forzosamente tienen que ser interpretadas por los demás a través de ademanes y conductas fuera de lo común.

Por ello, el interés principal de este trabajo es tratar de sugerir un método de lecto escritura que apoye al proceso de comunicación de la persona con autismo, centrándonos no tanto en el proceso lecto escritor en cuanto tal, sino como un medio a través del cual se pueda expresar la persona esto nos llevó a considerar ciertos puntos de partida entre los que destacan los elementos caracterológicos y conductuales, empezando por mencionar que en el autismo, la persona se encuentra centrada en sí misma, presentando un desorden severo y profundo de la conducta en donde el sujeto se encuentra inmerso en su propio ser y generalmente carece de capacidad para prolongarse hacia los demás.

En el autismo, los primeros síntomas aparecen en la primera infancia y se caracteriza básicamente por mostrar una indiferencia hacia las demás personas y al entorno que lo rodea, varian- 
do de intensidad de persona en persona. El autista generalmente presenta una conducta muy repetitiva y el lenguaje comúnmente se encuentra bastante alterado, tanto en la adquisición como en la expresión.

\section{EVOLUCIÓN HISTÓRICA}

Haciendo un poco de historia, podemos ver que el autismo es un síndrome recientemente sistematizado es hasta 1943 que el investigador Leo Kaner describe acertadamente las características sintomatológicas del autismo. Afirma que este padecimiento se origina por factores de índole familiar, pues la madre muestra rechazo y frialdad hacia el pequeño desde su concepción. Esto lo decidió a establecer la teoría de la "madre refrigerador". Obviamente, esta teoría trajo severos problemas de índole familiar y originó serios conflictos entre los padres. Ya en la actualidad, esta teoría ha quedado totalmente descartada y obsoleta.

Gracias a los estudios realizados por Kaner, se abrieron las puertas a investigaciones posteriores. Ya en la actualidad, se describe al autismo considerándolo como un síndrome que se presenta desde el nacimiento y se manifiesta casi invariablemente durante los 30 primeros meses de vida, cuando la respuesta a los estímulos visuales, auditivos y táctiles son anormales. Presenta además, severas dificultades en la emisión del lenguaje oral. Hay generalmente un retardo en el desarrollo lingüístico y si éste llega a desarrollarse, se encuentra contaminado con fallas principales de ecolalia, estructura inmadura e incapacidad para emplear términos abstractos. Además de estas fallas estructurales, se observa un deterioro en el empleo del lenguaje social y gesticular.

\section{CARACTERÍSTICAS BÁSICAS}

En cuanto al área social, ésta presenta serias deficiencias. Especialmente muestra conductas anómalas que impiden un ade- 
cuado desarrollo de esta área. Los problemas de las relaciones sociales generalmente se dan antes de los 5 años y son muy graves, incluyendo un defecto en el desarrollo de la mirada directa de los ojos y del juego cooperativo y social. Es frecuente encontrarnos con comportamientos ritualistas que pueden incluir rutina anómala con movimientos estereotipados, así como cierta resistencia al cambio, apego a objetos extravagantes y patrones estereotipados de juego.

Su capacidad para el pensamiento abstracto simbólico y para juegos imaginativos aparece disminuido.

$\mathrm{Su}$ actuación es mejor generalmente en los sectores relacionados con la memoria rutinaria o con las habilidades espacio visuales en comparación con aquéllas que exigen habilidades simbólicas o lingüísticas."

Hay que mencionar también que las personas con autismo no presentan anormalidades físicas aparentes generalmente, sino por el contrario, despliegan un aire de simpatía que llama la atención a las demás personas.

Realizar un diagnóstico de autismo no es una tarea sencilla. Puede haber gran confusión con otras manifestaciones o cuadros clínicos. A partir de los estudios realizados por Leo Kaner, se han propuestos diferentes métodos y criterios para realizar un diagnóstico más acertado. En la actualidad, los criterios que son más aceptados por su rigor científico y sistematización son los propuestos por la American Psychiatric Association, publicados en el DSM IV (1994) [Manual Diagnóstico y Estadístico de Enfermedades Mentales] en donde se especifica que existe deterioro conductual del sujeto autista, presentando básicamente un deterioro cualitativo de la interacción social, alteración cualitativa de la comunicación verbal y no verbal y un repertorio restringido de intereses y actividades. Así, la persona autista, aunque no presenta todas las conductas descritas dentro de los criterios básico, por lo menos debe presentar una cierta cantidad de conductas que se ajusten a las descritas en los patrones diagnósticos. 


\section{ETIOLOGÍA}

A la fecha, no se sabe con exactitud cuáles son los factores causantes del síndrome autista. Lo que sí queda muy claro es que al autismo se le conoce principalmente por sus manifestaciones. En la búsqueda de su etiología, se han podido establecer una serie de teorías que intentan dar una aproximación sobre su origen. Entre estas teorías podemos encontrar:

* Psicogénicas que se enfocan hacia un trastorno de tipo afectivo-emocional.

* Bioquímicas que intentan dar una explicación basadas en trastornos y disfunciones de tipo bioquímico-metabólico corporal.

* Virales que intentan relacionar al autismo con infecciones ocurridas en el período neonatal o en la primera infancia.

* Cognitivas que intentan relacionar al autismo con fallas en los componentes cognitivos innatos.

* Genéticas que intentan asociar al síndrome autista con fallas de índole cromosómico.

\section{DESARROLLO DE LA INVESTIGACION, ORIGENES}

A pesar de todas las limitaciones que la persona autista presenta, es innegable que tiene derecho a la comunicación y a la expresión general de sus ideas, sentimientos, pensamientos, etc. Gracias a la voluntad y esfuerzo de una serie de investigadores educativos, Itziar Zubillaga, Edith Salcedo, Elizabeth Bolivar, Evelia Vázquez y Liliana Villegas que han colaborado en forma estrecha y desinteresadamente dentro de mi equipo de trabajo, hemos investigado intensamente sobre los métodos didácticos más idóneos y que mejor se adapten a las características de los educandos que padecen autismo a fin de crear un sistema múltiple de comunicación a través del proceso de la lecto-escritura con apoyo de técnicas de "Comunicación Facilitada". Así, desde 1993, se empezó a realizar la investigación con la intención de crear e investigar las posibilidades lecto-escritoras de las personas autistas. 
Se planteó la hipótesis de que los métodos de marcha analítica o globales debido a la concreción y significado de sus contenidos eran más efectivos para el aprendizaje de la lectoescritura del adolescente autista sin lenguaje oral que los métodos de marcha sintética. A partir de esta hipótesis se empezaron a trabajar métodos globales como el método Global de Freire o de la Palabra Generadora, método Global de Minjares, el Método Luciérnaga y finalmente, se intentó comparar el aprendizaje obtenido a través de este tipo de métodos, contra el aprendizaje a través de un método de marcha sintético fonético como el Método Sintético Basurto o Mis primeras letras.

Los resultados obtenidos hasta la fecha han corroborado que la hipótesis planteada inicialmente, es la adecuada. En los tres primeros métodos aplicados -los globales -, la persona autista había adquirido el aprendizaje de la lecto-escritura, en tanto que en el último -el sintético-, no se alcanzaron los objetivos planteados. Gracias a los resultados obtenidos, se empezó a estructurar y plantear un método global específico que diera mayor eficacia y eficiencia al aprendizaje lecto-escritor. De esta forma surge el MÉTODO BEILEE, el cual conjunta todos los elementos didácticos y cognitivos necesarios para funcionar como un medio de comunicación no verbal efectiva. Sin embargo, es necesario corroborar la eficacia de este método que en la actualidad, se está evaluando y ampliando a una población mayor.

Haciendo una descripción más detallada de los resultados obtenidos (que dieron origen al Método BEILEE), es necesario describir las características propias de cada uno de los sujetos que han participado, así como los resultados obtenidos. Para ello, identificaremos los resultados de la aplicación del Método Freire como control 1, los del Método Minjares como control 2, los del Método Luciérnaga como control 3 y finalmente, el del Método Basurto como control 4. 


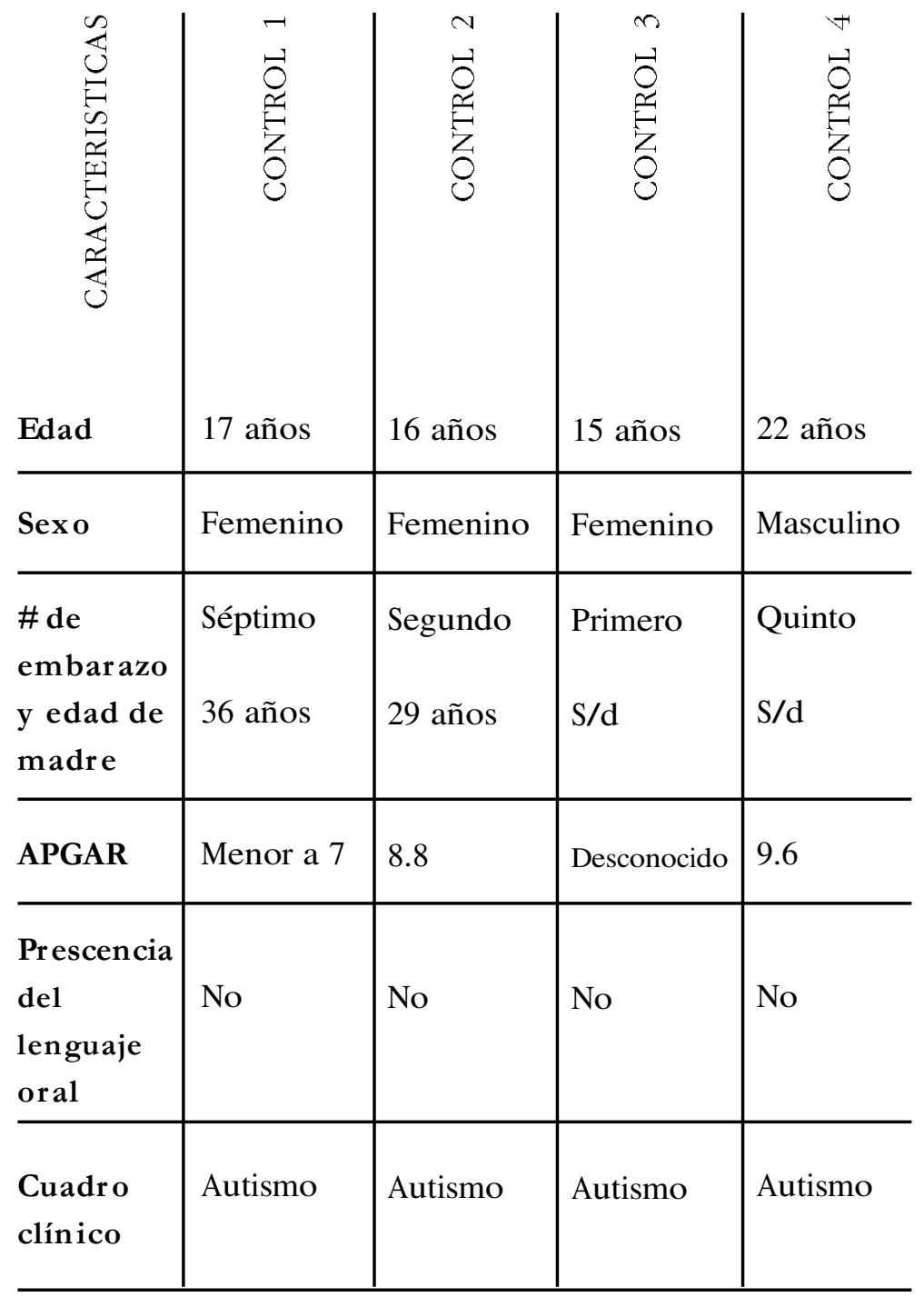

Tabla 1: Características de los sujetos 
En cuanto al contenido, en los 4 métodos empleados se empezó con la enseñanza de las vocales, continuando con la presentación de las consonantes. En el control 1 se manejaron 4 palabras generadoras. En el control 2 se utilizó también este tipo de palabras pero el orden en que se enseñó fue diferente. En el control 3 se utilizó una serie de frases para presentar las consonantes $y$, finalmente, en el control 4 se presentaron las consonantes aisladas y, posteriormente, en combinación con las vocales formando carretillas.

Por lo que respecta a la metodología, los cuatro métodos incluyeron una etapa preparatoria o de inducción a fin de preparar al alumno para sensibilizarlo dentro del contexto de la lecto-escritura y una segunda etapa de adquisición, por lo que en el control 1, se empleó la técnica de foto-palabra, en el control 2 se empleó la técnica de narración y cuento, en el control 3 se empleó el ejercicio global de reconocimiento y el control 4 se hizo a través de lectura de palabras y juego con vocales. Se advierte que dadas las características de los métodos, se tuvieron que realizar cambios y ajustes a la metodología propia de cada uno de ellos y por ello, en el control 1 solamente se llevaron a cabo la práctica de tres de las cinco fases metodológicas y técnicas del método, mientras que en el control 2, se lograron dos de cuatro y no de forma completa; en el control 3, se aplicaron todas las etapas marcadas en el método y en el control 4, la aplicación se suspendió al finalizar la primera fase del método por no haberse obtenido resultado de ninguna especie. Asimismo, es importante hacer mención que en los cuatro métodos se empleó una gran cantidad y variedad de recursos materiales, de acuerdo a los contenidos y metodología específica en cada uno de ellos.

En cuanto al tiempo didáctico, éste fue variable, pues dependió básicamente de las características propias del educando y la situación conductual de cada uno de ellos; sin embargo, el tiempo de sesión planeado fue de $30 \mathrm{~min}$. , como máximo; a pesar de 
dicha planeación, en el control 1 el tiempo promedio de sesión fue de 15 minutos, con un total de 45 sesiones; en el control 2 el tiempo de sesión fue 30 minutos con total de 54 sesiones; en el control 3 el tiempo de sesión fue de 25 minutos con total de 59 sesiones y, finalmente, en el control 4 el tiempo de sesión fue de 30 minutos con total de 79 sesiones.

Los resultados obtenidos nos muestras los siguientes datos:

\begin{tabular}{|c|c|c|c|c|}
\hline $\begin{array}{l}0 \\
0 \\
0 \\
0 \\
0 \\
0 \\
0 \\
0\end{array}$ & 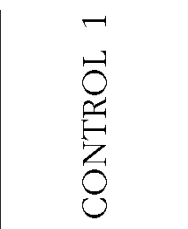 & $\begin{array}{l}N \\
0 \\
0 \\
0 \\
0 \\
0\end{array}$ & $\begin{array}{l}n \\
0 \\
0 \\
0 \\
0 \\
0\end{array}$ & $\begin{array}{l}- \\
0 \\
0 \\
0 \\
0 \\
0\end{array}$ \\
\hline Método & Freire & Minjares & Luciérnaga & Basurto \\
\hline Marcha & Analítica & Analítica & Analítica & Sintético \\
\hline $\begin{array}{l}\text { Unidad } \\
\text { mínima } \\
\text { lectora }\end{array}$ & Palabra & Palabras & Frases & Letras \\
\hline $\begin{array}{l}\text { Conocimiento } \\
\text { de palabras } \\
\text { lenguas o } \\
\text { frases }\end{array}$ & $\begin{array}{l}\text { Palabras } \\
\text { Generadoras }\end{array}$ & $\begin{array}{l}\text { Palabras } \\
\text { Generadoras }\end{array}$ & $\begin{array}{l}\text { Todas las } \\
\text { frases }\end{array}$ & $\begin{array}{l}\text { Vocales y } \\
\text { cuatro } \\
\text { consonantes }\end{array}$ \\
\hline $\begin{array}{l}\text { Palabras } \\
\text { formadas }\end{array}$ & Cualquiera & $\begin{array}{l}35 \text { palabras y } \\
18 \text { frases }\end{array}$ & Cualquiera & Ninguna \\
\hline $\begin{array}{l}\text { Logros } \\
\text { del método }\end{array}$ & $\begin{array}{l}\text { Puede formar } \\
\text { frases, se } \\
\text { logró } \\
\text { establecer } \\
\text { comunicación } \\
\text { con otra } \\
\text { persona }\end{array}$ & $\begin{array}{l}\text { Puede formar } \\
\text { frases, se } \\
\text { logró } \\
\text { establecer } \\
\text { comunicación } \\
\text { con otra } \\
\text { persona }\end{array}$ & $\begin{array}{l}\text { Puede formar } \\
\text { frases, se } \\
\text { logró } \\
\text { establecer } \\
\text { comunicación } \\
\text { con otra } \\
\text { persona }\end{array}$ & $\begin{array}{l}\text { No logró } \\
\text { escribir, por } \\
\text { lo que no } \\
\text { pudo } \\
\text { establecer } \\
\text { comunicación } \\
\text { con otra } \\
\text { persona }\end{array}$ \\
\hline
\end{tabular}




\section{NUEVAS ESPERANZAS: EL METODO BEILEE}

Partiendo de estos datos y resultados, se procedió a diseñar e instrumentar un método lecto-escritor específico para personas autistas denominado BEILEE (el cual toma las iniciales de sus creadoras), que tiene como objetivo primordial el "desarrollar la habilidad comunicativa del adolescente autista mediante el proceso de la lecto-escritura" y para ello, el método se centra en 5 vertientes o ejes temáticos, a saber: a) familia, b) vestido, c) alimentos, d) hogar, e) noción corporal.

La metodología empleada considera los principios establecidos en los métodos de marcha analítica, por lo que la unidad mínima lectora será la palabra. Así, se establecen 7 módulos metodológicamente secuenciales:

* $1^{\circ}$ Estimulación motriz

$* 2^{\circ}$ Aprendizaje de su nombre

$* 3^{\circ}$ Aprendizaje de las 5 vocales

* $4^{\circ}$ Presentación de la familia

$* 5^{\circ}$ Aprendizaje de las consonantes primarias

$* 6^{\circ}$ Aprendizaje de las consonantes secundarias

$* 7^{\circ}$ Aprendizaje de las consonantes terciarias

El tiempo destinado para cada sesión deberá tener como mínimo una duración de 30 minutos, distribuido de la siguiente manera:

* Rapport => duración de 3 a 5 minutos como máximo

* Trabajo académico => 20 minutos como mínimo

* Cierre $=>$ de 3 a 5 minutos como máximo.

El total de sesiones será variable dependiendo de las características de cada educando, así como del avance y logro que el mismo muestre; sin embargo, se han establecido como mínimo 63 sesiones para cubrir el método.

Por lo que respecta al material didáctico, se han diseñado distintas láminas para el manejo de algunos módulos, así como material complementario de estimulación y enseñanza. Sin em- 
bargo, es posible que el educador pueda crear material extra a fin de reforzar las imágenes y palabras que se presentan en cada uno de los diversos módulos siempre y cuando se atenga a las directrices señaladas y objetivos especificados.

De igual manera, se han creado protocolos de evaluación con el fin de llevar a cabo un registro minucioso de los avances modulares de los educandos, sin embargo, se recomienda realizar evaluación sesión tras sesión a fin de determinar y reforzar el aprendizaje del educando.

Concluyendo, podemos decir que se tiene una gran fe en los resultados que puede arrojar este método, puesto que abrirá una puerta de esperanza a todas las personas que padecen autismo, así como a sus seres queridos, ya que finalmente podrán romper las barreras y ataduras del silencio que les ha sido impuesto.

\section{REFERENCIAS BIBLIOGRÁFICAS}

1.- apud., GARANTO A., JESÚS; EL AUTISMO., pp. 31-32

\section{BIBLIOGRAFIA}

1.- GARANTO ALOIS, Jesús ; EL AUTISMO, Ed. Herder Barcelona, 1990

2.- AMERICAN PSYCHIATRIC ASSOCIATION ; MANUAL DIAGNÓSTICO Y ESTADÍSTICO DE LOS TRASTORNOS MENTALES. DSM IV. Ed. Masson México, 1995

3.- PALUSZNY, María ; EL AUTISMO., Ed. Trillas México, 1991 